\title{
Production and properties of alternative aviation fuels
}

\author{
Martin Voráček \\ Department of Air Transport, \\ Department of Air Transport, Faculty of Transportation \\ Sciences, Czech Technical University \\ Horská 3, Praha 2, 128 03, Czech Republic \\ e-mail: voracma1@fd.cvut.cz
}

\author{
Jakub Kraus \\ Department of Air Transport, \\ Department of Air Transport, Faculty of Transportation \\ Sciences, Czech Technical University \\ Horská 3, Praha 2, 128 03, Czech Republic \\ e-mail:kraus@fd.cvut.cz
}

\begin{abstract}
This article focuses on alternative fuels in aviation and their production and properties. It also points out current challenges, which must be overtaken by these successors of petroleum.
\end{abstract}

Keywords-Alternative fuels, VHO, HRJ, Flights with biofuels.

\section{INTRODUCTION}

A lot of alternative fuels are used in every type of transport, but by far not all of them are suitable for application in air transport. Aviation fuels must exactly meet the defined specifications, because modern aircraft engines are designed to maximize the use of fuel properties. Aviation fuel must also reliably deliver energy to the engines in a large range of temperatures and pressures while meeting the requirements necessary for the proper operation of control elements, fuel delivery elements and injection and combustion systems.

The air transport is dependent on oil from $98 \%$ today, whose reserves are still shrinking. It is therefore necessary to look for other ways to reduce these numbers as quickly and efficiently as possible.

\section{REQUIREMENTS FOR AVIATION FUELS}

The main purpose of the technical requirements for aviation fuels is to ensure safety of air transportation. Since undergoing a range of devices and systems, the fuels must be compatible with all materials used. Any change in the used fuel must be very carefully assessed and must be considered whether it will not affect the performance of engines or aircraft as a whole.

\section{PRODUCTION AND PROPERTIES OF ALTERNATIVE} AVIATION FUELS

Aviation fuels can be divided into several basic groups:

- Miscible

○ Conventional fuels - produced by established procedures from crude oil raw materials

○ Unconventional oil fuels - based on crude oil from unconventional resources

- Synthetic fuels - from synthesis gas by FischerTropsch synthesis

- Sustainable fuels - from biomass, vegetable oils or animal fats
- Non-miscible - based on the use of completely new technologies and processes

Alternatively, alternative aviation fuels can be divided into two groups:

- so-called "drop-in" fuels, which are miscible with conventional fuels and applicable in the current aircraft using the existing infrastructure, and

- "non-drop-in" fuels, the use of which requires changes in the structure of aircrafts and their engines, and building a new infrastructure. Development and approval of these fuels will be an issue in the next few decades.

And nowadays, "drop-in" fuels can be produced only by three ways:

- An alternative method for obtaining oil from oil sands, VHO (very heavy oil) and oil shale (not alternative fuels as such)

- Gasification of raw materials to synthesis gas and its processing by Fischer-Tropsch synthesis

- Fuels called Hydro-processed Renewable Jet (HRJ)

\section{A. Conventional air fuels}

Aviation fuels are divided into two basic groups - aviation gasoline used in piston engines and aviation kerosene, used to drive turbine engines.

Conventional air fuels are produced from crude oil, which contains a number of molecules. Each of them consists of carbon and hydrogen atoms (hydrocarbons - alkanes, aromatics, naphthalene, and olefins) and may contain atoms of other substances, such as sulphur, nitrogen, oxygen, phosphorous and various metals. Molecules possess different properties, which mainly depend on the number of carbon atoms and their mutual arrangement. Generally we can say that with the increasing number of carbon atoms in the molecule, the boiling point, crystallization point and the energy contained in unit volume are increasing. On the other hand, volatility and energy content per unit mass or heating value are decreasing.

Crude oil fuels are produced through refining, which is, generally speaking, the process of cleaning substances. In the case of crude oil fractionation, it is a chemical transformation with the aim to improve the characteristics of refinery products. The most important step is distillation, in which the individual 
fractions are separated based on different volatility (boiling point) to meet the demands placed on the particular fuels. The mixture is heated to boiling point and richer part of the more volatile component passes into the gaseous phase. It condenses in the heat exchanger and this way, a distillate with a higher proportion of more volatile components than the original mixture, is obtained. Cracking, centrifugation or other processes may also be part of the refining.

\section{B. Unconventional crude oil fuels}

For the production of unconventional oil-based fuels, three ingredients - Canadian oil sands, Venezuela's so-called "very heavy oils" ("very heavy oils", VHO) and oil shale, can be used. All these three ingredients shown, that they meet all requirements for the production of kerosene. The production is more energy-intensive (both surface mining and subsequent processing) than for conventional fuels, resulting in increased emissions by about $10 \%-25 \%$. Combustion of fuel itself does not bring any difference as compared to conventional fuels in emissions. Problematic aspect of these fuels is a major intervention into the landscape at the mine site. As in the case of other alternative fuels, due to the rising crude oil price, the interest in the unconventional petroleum fuels is increasing.

\section{Synthetic fuels}

The synthetic fuels are produced by Fischer - Tropsch synthesis from coal (CTL, coal-to-liquid), biomass (BTL, biomass-to-liquid) or gas (GTL, gas-to-liquid). These fuels are miscible with conventional fuels, and some of their properties are even better than the parameters of the conventional fuels. They are also compatible with existing infrastructure. In 2009, ASTM (American Society for Testing and Materials) approved the use of synthetic fuels in aviation, particularly as a mixture with the fuel JET A-1 and later even $100 \%$ synthetic fuel produced by CTL method.

\section{1) Production of synthetic fuels}

Production of synthetic fuels consists of three steps. The first one is the production of synthesis gas (a mixture of $\mathrm{H} 2$ and $\mathrm{CO}$ in particular, but also $\mathrm{CO} 2$ and other gases) by gasification of biomass or coal (or combination of these materials) or partial oxidation of natural gas. The resulting synthesis gas has similar properties; selection of raw materials, however, plays an important role in its production potential, production costs, emissions and fuel technologies. It is further cleaned (removal of undesirable compounds and substances such as sulphur and others, adjusting the ratio of $\mathrm{H} 2$ and $\mathrm{CO}$ ) and then, with the assistance of Fischer - Tropsch synthesis, synthetic crude oil is produced, from which via the subsequent classical refining the aviation fuels are obtained. Synthetic fuels are highly paraffinic (with direct hydrocarbon chains) and therefore, as compared to conventional fuels, they contain a very small amount of aromatics, olefins and naphthalene. For this reason, during their combustion, only small emissions of solid particles occur.

In addition, it can be used directly as a fuel in power plants and stationary applications, or it can be used for production of a number of chemicals that have been up to now produced mainly from petroleum, such as methanol, dimethyl ether, ammonia, light alkenes, and other petrochemicals.

\section{2) Properties of synthetic fuels}

The benefits of synthetic fuels include cleaner combustion without emission of sulphur and nitrogen oxides (SOx, NOx) and lower particulate emissions, higher thermal stability (no sedimentation of carbonaceous residues in the fuel system) and excellent low temperature properties (low viscosity), resulting in better performance at higher levels, lower maintenance requirements and easier and more reliable engine starting at low temperatures.

The disadvantage are worse lubricity, low aromatic content (causing problems in fuel systems), and higher $\mathrm{CO} 2$ emissions in their manufacture. Synthetic fuels (excluding technology BTL) are produced from non-renewable resources.

\section{3) Utilization of synthetic fuels in aviation}

Testing of synthetic fuels was first conducted on the test engine CFM56-7B, and since 2008 also in flight. Tests revealed no difference in engine behaviour compared to engines using conventional fuels and have shown that synthetic fuels meet the requirements for aviation fuels. On their basis, synthetic fuel was approved for commercial use in a mixture of 50:50 with Jet A and Jet A-1 fuels. Synthetic fuels are available only on a limited number of airports.

The first flights with pure synthetic fuel took place only in 2010 because there were fears that the low aromatic content could cause problems in the fuel system (certain types of elastomers used as sealing expand in the contact with the aromatics contained in the conventional fuel, but using fuel with less aromatics could cause their shrinking and this could lead to leakage of fuel) and that its reduced lubricity could lead to increased wear of engines.

These problems were solved using the Fischer-Tropsch synthesis at high temperatures and a catalyst based on iron. The result is similar content of aromatics as in conventional fuels. These fuels are referred to as SKA (Synthetic Kerosene with Aromatics), and their approval for commercial flights is expected shortly.

Synthetic fuels have higher energy values contained in the mass unit, however, they contain less energy per unit volume. For air transport, it follows that their use in aircraft flights at the same distance (as compared to conventional fuels, such as Jet A), the mass of the burned fuel is smaller. In contrast, the maximum range of the airplane is reduced (the volume of fuel on board is limited by the capacity of fuel tanks).

A pioneer in the development of synthetic aviation fuels is company Sasol from South Africa, great support to these fuels is provided also from the U.S. Air Force. The first commercial flight with a mixture of conventional and synthetic fuel was performed in 2009 by Qatar Airways. Synthetic fuel from Shell Company, produced on the GTL basis, powered Airbus A340600 equipped with Rolls-Royce engines, on a six-hour long flight from London to Douhá. The first flight on a clean synthetic fuel produced by Sasol Company by CTL technology was held on 22 September 2010 in South Africa on the route from Johannesburg to Cape Town. 


\section{Sustainable aviation fuels}

Sustainable aviation fuel can be defined as a fuel without negative environmental, economic and social impacts. It should exhibit lower overall emissions of greenhouse gases, obtaining raw materials for its production should also not hamper food production, reduce sources of drinking water and should not require cutting down forests.

\section{1) Bio kerosene}

Bio kerosene is kerosene derived from biomass. However, bio kerosene has not become widely used in aviation because it has been unable to meet the technical requirements of aviation fuel, such as high energy content per volume and a low freezing point. Until very recently, bio kerosene for aviation fuel was not viewed as a realistic alternative to traditional fossil fuels. Possible sources for bio kerosene include synthetic biofuels made by gasifying biomass liquefied by the FischerTropsch process, and green diesel based on a hydrogenation process of vegetable oils.

Due to the not very good characteristics and availability of other alternative fuels, authors does not suppose its larger spreading, it could be applied in a small percentage as an additive to conventional petroleum fuels.

\section{2) Hydro-processed Renewable Jet (HRJ)}

Production of these fuels is based on the direct conversion of oils to hydrocarbon fractions. The processes performed in the presence of hydrogen appear to be the most promising way of conversion of vegetable oils to hydrocarbons.

After harvesting of raw materials, the oil is obtained by stamping. Waste is further processed (to feeds, ...). The main difference between fossil and renewable raw materials is the content of heteroatoms, particularly oxygen. In terms of compatibility of alternative fuels it is therefore crucial to eliminate oxygen. HRJ production consists in the removal of oxygen with the help hydrodeoxygenation when in the reaction with hydrogen atoms oxygen atoms are removed in the form of water. The resulting hydrocarbons undergo isomerization and cracking in order to reduce the number of carbon atoms in the chain corresponding to a range of aviation fuels. In this way, the required properties such as crystallization point and flash point are achieved.

Properties of the resulting synthetic fuel are similar to fuels obtained by Fischer-Tropsch synthesis, it means with almost no sulphur content and high thermal stability. The disadvantages include reduced lubricity and minimum content of aromatics. As with synthetic fuels, the solution is the usage of additives or blended fuels of petroleum origin. HRJ fuels have been approved for commercial use in blends with conventional fuels in ratio 50:50 in summer 2011.

\section{3) Raw materials used for production of biofuels}

The issue of resources remains problematic. If we want biofuels to power all aircraft, it means annual consumption of about 60 billion gallons [6]. Using raw materials such as soy, canola or sugar cane, not only can disrupt food supplies and increase their price, but also brings with it an increase in greenhouse gas emissions (planting, harvesting crops, increasing areas of agricultural land - deforestation) and negatively affects the environment (using fertilizers and pesticides). To be considered a sustainable fuel, it is necessary to find a material that suppresses these negative effects to a minimum - material, which will not hamper food production, agricultural land or drinking water. In addition, it must be available in sufficient quantity and worldwide. It is obvious that we cannot be limited to one material. Application of mixture of different sources in combination with conventional fuels appears to be the most likely solution. The best raw material for biofuel crops seems to be the following:

\section{a) Jatropha}

The plant, whose seeds contain oil in 30-40\% of their mass. The seeds are toxic to both humans and animals; this is not a food source. It can grow in dry, otherwise unusable land. Remains from the production of biofuels can be used as fuel in boilers and stoves.

\section{b) Camelina}

It is Energy-rich crop with high oil content. The main goal of its cultivation is the production of renewable fuels, production residues can be used in small doses as feed. It is an easy crop, grown in soils that would otherwise remain unplanted.

\section{c) Algae}

Perhaps the most promising raw material for biofuel production is Algae. These are able to produce sufficient quantities of fuel, moreover, they grow in polluted and salty water, deserts and other inhospitable places. They do not occupy the fertile soil suitable for growing food. The big advantage is the speed of their growth and yields, which are per square kilometre up to 15 times greater than for other raw materials. Waste from production is used as fertilizer or feed.

\section{d) Halophytes}

These grasses are growing in salt marshes and some species also in salt water. Halophytes are used for the production of third generation biofuels.

For the production of biofuels, the waste animal fats and cooking oils can also be used. By the cultivation of Halophytes and by using the waste fats and oils could be achieved sufficient global production of biofuels.

\section{FLIGHTS WITH BIOFUELS}

Since the approval of HRJ fuels was held a number of test flights. Longer-term testing was conducted in the period from July to December 2011 by Lufthansa on the route Hamburg Frankfurt, where one of the engines of the Airbus A321 was powered by a mixture of conventional and biosynthetic kerosene in the ratio 50:50. It was a total of 1187 flights, the consumption of biofuels was 1556 tons and according to current calculations, the $\mathrm{CO} 2$ emissions were cut by 1471 tons. Lufthansa is also testing biofuel on transatlantic flights, the first of them successfully passed the 12th January 2012 on the flight LH418 Frankfurt - Washington and the tests are continuing. Calculations show that if Lufthansa would use biofuel on all its flights to the United States (approximately 
400 flights a week), it would mean a weekly savings of about 15,000 tons of $\mathrm{CO}_{2}$ emissions. Lufthansa uses mostly a mixture of oil from Camelina plants originating from the U.S., complete with Jatropha oil from algae from Brazil and animal fats from Finland.

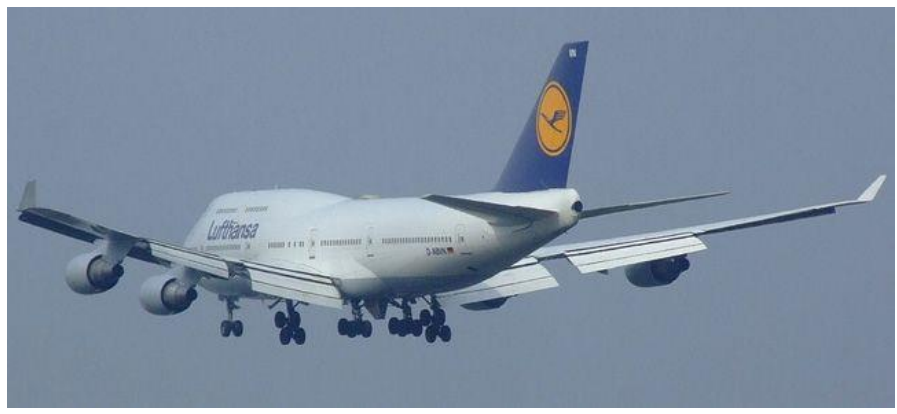

Figure 1. First LH418 flight on biofuels [5]

However, the very first transatlantic flight powered with biofuel mixture with conventional kerosene (15\% algae-based biofuel Jatropha) was the flight of Boeing 747-800F from Everett to the Paris Air Show in which four GEnx-2B engines were driven by biofuel.

\section{CONCLUSION}

In these article was shown and described alternative fuels for aviation with theirs pros and cons. The alternatives got huge potential for future, but today, their worldwide usage is only at start. The best alternative fuel for immediate use is socalled "drop-in" fuel. This is the one currently already approved or under approval. But perhaps even more chances are directly in HRJ, because of their renewability. However, it is important to analyse possible space for growing as not to affect too much of the agricultural land in terms of crops for food.

The arrival of all alternative fuels is slowed by the greatest possible obstacle - today, their production is more energy consuming than oil use. And this needs to be changed.

\section{REFERENCES}

[1] ŠEBOR, Gustav, POSPÍŠIL, Milan a ŽÁKOVEC, Jan. Technickoekonomická analýza vhodných alternativních paliv v dopravě. Praha : VŠCHT, Fakulta technologie ochrany prostředí, 2006.

[2] IATA 2011 Report on Alternative Fuels. Montreal, Geneva : International Air Transport Association, 2011.

[3] KUBIČKA, David, ŠIMÁČEK, Pavel a ŠEBOR, Gustav. Transformace rostlinných olejů na uhlovodíky. Praha: Výzkumný ústav anorganické chemie, VŠCHT Praha, 2007.

[4] Fact Sheet: Alternative Fuels. IATA. [Online] IATA, 1. 12 2011. [cit. 13. 5 2013.] Available at:

$<$ http://www.iata.org/pressroom/facts_figures/fact_sheets/pages/altfuels.aspx>

[5] Lufthansa 747 operates first transatlantic biofuel flight to US. Air News Times. 2012. [online]. [cit. 23.7.2013] Available at: <http://www.airnewstimes.co.uk/lufthansa-747-operates-first-transatlanticbiofuel-flight-to-us-13558-news.html>

[6] World Jet Fuel Consumption by Year. Index mundi. [online]. [cit. 14.8.2013] Available at:

$<$ http://www.indexmundi.com/energy.aspx?product=jet-

fuel\&graph=consumption>
[7] NINGER, Jakub. Bakalářská práce, Praha: ČVUT - Fakulta dopravní, 2012 